Es cansino una de esas voces oscuras cuyo nacimiento y desarrollo apenas si podemos vislumbrar aun cuando usamos los métodos de análisis más rigurosos. Son demasiado escasos y, sobre todo, demasiado tardíos los materiales para permitir una reconstrucción enteramente satisfactoria.

Pero ya se adivina la trayectoria que conduce de $\operatorname{camp}(e)$ sino, nombre propio de la alta Edad Media, a la voz rústica cansino que sobrevive en los dialectos (rodeada de sus formaciones satélites cansinado, acansinado, acansinadico, cansina), al cansino de Pérez Galdós y al cansino un tanto ennoblecido de los poetas modernistas. Ya se entrevé la importancia que hay que conceder al cruce del antiguo derivado de campo con el verbo cansar y su legítima progenie. Dentro de este desarrollo, la aplicación (poco duradera) del apodo cansino a los hebreos, motivada por el prestigio de una familia argelina que llevaba ese apellido, no es más que un episodio divertido, una anécdota linguística, que no dejará de encantar a todo el que se ocupe en la historia del siglo xvir.

University of California.

YAKOV MALKIEL

\title{
FRANCISCO IMPERIAL Y LAS VIOLENCIAS SEVILLANAS DE 1391
}

La Srta. María Rosa Lida, en su interesante artículo, Un Decir más de Francisco Imperial... (NRFH, I, 1947, págs. 175-177), arguye muy persuasivamente contra mi atribución a Imperial de una manifestación de antisemitismo militante en su Decir a las siete virtudes (Sp, xxi, 1946, págs. 460-462). Tan persuasivamente, en efecto, que yo estaría dispuesto a guardar silencio, a no ser por el hecho de que uno de mis propios argumentos ha carecido evidentemente de claridad y por esto ha dado lugar a una impresión incorrecta. Me refiero al significado de raza. Mi propia interpretación de esta palabra es exactamente la de la Srta. Lida: raça, 'defecto', 'tacha'<radia. Pero ella cree que en la copla 50 se trata de ejercerse la justicia real, mientras que yo la entiendo de otra manera (véase mi antedicho artículo); aunque, a decir verdad, en uno y otro caso el efecto en los nombrados culpables por Imperial (judíos, moros, etc.) no dejaría de ser más o menos el mismo: el derramamiento de su sangre ${ }^{1}$. Además, en el año de 1391 (véase mi artículo, pág. 460), una condena de los judíos sevillanos, por vaga que fuese, no habría dejado de aumentar a los ciudadanos sevillanos ya conocedores del poema de Imperial cualquier resentimiento ya existente a fuerza de las exhortaciones de Ferrand Martínez de Écija y los graves abusos municipales (mencionados por Imperial, op. cit., copla 46).

El empleo de la alegoría para quejarse de abusos locales o nacionales, y para condenarlos, es cosa muy corriente en la época de la que es cuestión aquí: en el Cancionero de Baena son ejemplos de esto los poemas de la edición de Ochoa numerados 57 (de Villasandino); 288, 291, 292 (de Páez de Ribera); 297, 320

mente significaba 'declive, llanura', estando estrechamente relacionado con el gr. xauлฑ' 'curva, flexión', preservado en romance como gamba, y sobre todo con $\chi \alpha ́ \mu \tau \tau \omega$ 'doblar, encorvar', de cuyo aoristo

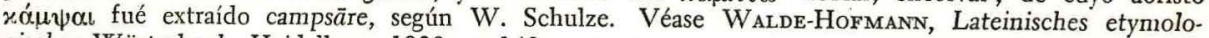
gisches Wörterbuch, Heidelberg, 1938-, I, 148.

1 [La discrepancia está en que para la Srta. María Rosa Lida, Imperial reclama la justicia real para los tradicionalistas enemigos de la fe, moros, judíos y herejes; para el Prof. Place, Imperial abogaba por motines raciales ("race riots"). La copla 50, en la que una y otro han concentrado su a'cnción, dice así:

A los tus suçessores claro espejo será mira el golpe de la maça, será miral el cuchillo bermejo que cortará doquier que falle raza.] 
(de Pedro Vélez de Guevara); 335 (de Gonzalo Martínez de Medina); 348 (de Frey Lope de Monte); y 547 (de Fernán Pérez de Guzmán). Por eso sigo creyendo que Imperial, al escribir el Decir de las siete virtudes, se preocupaba mucho más por el estado, reconocidamente malo, de su ciudad adoptiva y por la aplicación de remedios fuertes, que por "las vagas condenas de todos los tradicionales enemigos de la fe cristiana" (palabras de la Sita. Lida, op. cit., pág. 175).

Sin embargo, reconozco que la Srta. Lida tiene razón en poner en duda mi conjetura acerca de la "good impression thecha por la manifestación de antisemitismo de parte de Imperial] on the educated contemporaries of Imperial (including Santillana's poet uncles...)", y por falta de pruebas retiro esta conjetura.

En conclusión, quisiera aprovecharme de esta ocasión para corregir la impresión corriente entre varios críticos españoles de que yo procurara, con mi artículo titulado The Exaggerated Reputation of Francisco Imperial, deprimir el ingenio poético de Imperial. Nada más lejos de la verdad. Mi artículo trata de un problema de historia literaria y de ninguna manera se ocupa con cuestiones de crítica literaria. Para mí, Francisco Imperial sigue siendo lo que siempre fué: un poeta de gran talento y a veces de verdadera inspiración poética - de hecho la voz más lírica de su época.

Northwestern University

EDWIN B. PLACE

\section{SOBRE LA DIFUSIÓN DE LA LEYENDA DEL PURGATORIO DE SAN PATRICIO EN ESPAÑA}

Ácerca de la tradición del purgatorio de San Patricio en España, creencia de origen extranjero, ha recogido todo lo conocido Antonio G. Solalinde, La primera versión española de "El purgatorio de San Patricio" y la difusión de esta leyenda en España, artículo inserto en el Homenaje a Menéndez Pidal, Madrid, 1925, II, págs. 219-257. Con posterioridad apareció la obra de C. M. van den Zanden, Etude sur le Purgatoire de Saint Patrice, Amsterdam, 1927, que poco o nada agrega acerca de la difusión en España. No he podido ver el artículo de P. Mac Bride, St. Patrick's Purgatory in Spanish literature, Studies in Irish Quarterly, 1936, xxv. Solalinde recoge únicamente los títulos de dos comedias en las cuales se utilice esta leyenda: El mayor prodigio y el purgatorio en la vida, atribuída a Lope de Vega ${ }^{1}$, y El purgatorio de San Patricio de Calderón de la Barca. La fuente de ambas comedias fué la obra del Dr. Juan Pérez de Montalván, Vida y purgatorio del glorioso San Patricio, arzobispo y primado de Hibernia, escrita por el doctor..., Madrid, $1627^{2}$.

Revisando el voluminoso Cancionero de 1628 editado por José Manuel Blecua ${ }^{3}$ encontramos la composición número 412 (pág. 490) cuyo epígrafe dice A María de Córdoba, en la comedia de San Patricio. Blecua supone (pág. 54) que esa comedia sería la de Calderón y por consiguiente quiere retrotraer la fecha de su composición hasta el año 1628. Conviene sutilizar un poco la investigación para evitar un error que podría tener consecuencias en la cronología calderoniana.

1 S. G. Morley y C. Bruerton (por no citar más que un estudio reciente), The chronology of Lope de Vega's comedias, New York, 1940, pág. 310, se inclinan a dudar de su autenticidad. Para ellos, "la obra, al menos en su forma presente, no es de Lope".

2 La novela de don Alonso de Castillo Solórzano, Tiempo de regocijo y carnestolendas de Madrid, Madrid, 1627, se halla precedida por unas palabras Al bien intencionado que suscribe el propio Montalván, quien anuncia la próxima publicación de su tratado acerca del purgatorio de San Patricio. (Cf. Colección selecta de antiguas novelas españolas, vir, Madrid, 1907, pág. 190).

3 Madrid, 1945, anejo xxxir de la RFE. Hace tiempo que la lírica peninsular no recibía un aporte de nuevos materiales de la importancia del presente Cancionero. El único inconveniente que presenta para su manejo es la defectuosa confección de los índices. 